\title{
Atmospheric pressure microwave torch for synthesis of carbon nanotubes
}

\author{
L Zajiččková ${ }^{1}$, M Eliáśs ${ }^{1}$ O Jašek ${ }^{1}$, V Kudrle ${ }^{1}$, Z Frgala $^{1}$, J Matějková ${ }^{2}$, \\ J Buršík ${ }^{3}$ and M Kadlečíková ${ }^{4}$ \\ ${ }^{1}$ Department of Physical Electronics, Masaryk University, Kotlářská 2, 61137 Brno, \\ Czech Republic \\ ${ }^{2}$ Institute of Scientific Instruments, Academy of Sciences of the Czech Republic, \\ Královopolská 147, 61264 Brno, Czech Republic \\ ${ }^{3}$ Institute of Physics of Materials, Academy of Sciences of the Czech Republic, Žižkova 513/22, \\ 61662 Brno, Czech Republic \\ ${ }^{4}$ Department of Microelectronics, Faculty of Electrical Engineering and Information Technology, \\ Slovak University of Technology, Ilkovičova 3, 81219 Bratislava, Slovak Republic \\ E-mail: lenkaz@physics.muni.cz
}

Received 1 July 2005

Published 10 November 2005

Online at stacks.iop.org/PPCF/47/B655

\begin{abstract}
The microwave (mw) plasma torch at atmospheric pressure has been studied for carbon nanotube (CNT) synthesis. The depositions were carried out on silicon substrates with 5-15 $\mathrm{nm}$ thin iron catalytic overlayers from the mixture of argon, hydrogen and methane. The optical emission spectroscopy of the torch showed the presence of $\mathrm{C}_{2}$ and $\mathrm{CH}$ radicals as well as carbon and hydrogen excited atoms. The vicinity of the substrate influenced the relative intensities and increased the emission of $\mathrm{C}_{2}$. For fixed mw power, the temperature of the substrate strongly depended on its position with respect to the nozzle electrode and on the gas mixture, particularly the amount of $\mathrm{H}_{2}$. The speed of the substrate heating during an early deposition phase had a significant effect on the CNT synthesis. An abrupt increase of the temperature at the beginning increased the efficiency of the CNT synthesis. Areas of dense straight standing CNTs, $30 \mathrm{~nm}$ in average diameter, with approximately the same sized iron nanoparticles on their tops were found in accordance with the model of growth by plasma enhanced chemical vapour deposition. However, the deposit was not uniform and a place with only several nanometres thick CNTs grown on much larger iron particles was also found. Here, taking into account the gas temperature in the torch, 3100-3900 K, we can see similarities with the 'dissolution-precipitation' model of the CNT growth by high temperature methods, arc or laser ablation.
\end{abstract}




\section{Introduction}

Using high temperature methods, carbon nanotubes (CNTs) can be produced from carbon vapour generated by an arc discharge [1] or by the laser ablation of graphite [2]. Alternative methods are covered by the term 'chemical vapour depositions' (CVD). The CVD group can be further divided into thermal CVD processes and processes utilizing plasma discharges, the so called plasma enhanced CVD (PECVD). In the case of the PECVD, various kinds of low pressure discharges such as microwave ( $\mathrm{mw})$ [3,4], mw electron-cyclotron resonance [5], dc glow discharges [6,7] and capacitive [8,9] and/or inductive [10,11] rf glow discharges have been applied. The reactants used for the production of CNTs are usually $\mathrm{CH}_{4}$ mixed with $\mathrm{H}_{2}$ but $\mathrm{C}_{2} \mathrm{H}_{2}, \mathrm{CO}$ or $\mathrm{C}_{3} \mathrm{H}_{4}$ mixed with $\mathrm{H}_{2}, \mathrm{~N}_{2}$ and $\mathrm{NH}_{3}$ were also tested [9]. In most of the low pressure PECVD experiments the catalyst thin film is deposited on the substrate or the metal nanoparticles are placed on the substrate before the CNT growth.

The employment of some type of atmospheric pressure discharge for CNT synthesis is relatively seldom. First attempts yielding randomly oriented MWNTs, 20-50 nm in diameter, have been made in an atmospheric dielectric barrier discharge [12]. Chen et al [13] reported the production of macro-sized woven threads of the CNTs by an argon plasma mw torch at atmospheric pressure using carbon monoxide as a carbon source and iron carbonyl as a source of the metal catalyst. Kikuchi et al [14] presented a novel rf microplasma jet at atmospheric pressure and showed the possibility of producing various carbon nanostructures including CNTs. Recently, we reported a deposition of dense and straight standing CNTs using a mw plasma torch at atmospheric pressure [15]. In the present paper we extend the previous study of the CNT deposition by improving the reactor and we discuss results on more precise substrate temperature measurements and plasma diagnostics for a better understanding of the deposition process.

\section{Experimental}

The whole experimental set-up used for the synthesis of CNTs and plasma diagnostics is described below. Microwave power is supplied by a $2.45 \mathrm{GHz}, 2 \mathrm{~kW}$ generator via a standard rectangular waveguide. A ferrite circulator protects the generator against the reflected power by rerouting it to the water load. At the end of the waveguide there is a broadband transition to a coaxial line by means of a ridge waveguide. The combination of a movable short plunger and a line stretcher act as an impedance transformer that can achieve the matching of any load (plasma) to the line impedance. The inner conductor of the coaxial line is a hollow double-walled tube accommodating a dual gas flow. A conical hollow nozzle electrode is fixed to its top. The nozzle is made of iron with a central gas flow channel, $1 \mathrm{~mm}$ in diameter. A set of holes in the outer tube wall allows for separate gas feeding by an outer channel. The central conductor is held in place by boron nitride ceramics. The outer conductor of the coaxial line is terminated by a flange. A detailed drawing of this part of the reactor is given in figure 1 .

The plasma expands from the central nozzle forming a torch discharge. A quartz tube, $40 \mathrm{~mm}$ in outer diameter, separates the discharge from surrounding atmosphere. At the bottom it is sealed by a teflon piece to the flange of the outer coaxial conductor. At the top it is closed by an upper flange with an exhaust tube and a sealed feedthrough for a substrate holder. The substrate holder is another quartz tube, $18 \mathrm{~mm}$ in outer diameter, fixed at the upper flange. This tube is closed at its top by a quartz window. At the opposite side, i.e. close to the discharge nozzle, two slits are cut through the tube. Substrates for the deposition $\left(15 \times 10 \mathrm{~mm}^{2}\right)$ are inserted into these $1 \mathrm{~mm}$ wide slits and pressed down slightly by the weight of a $20 \mathrm{~mm}$ piece of 

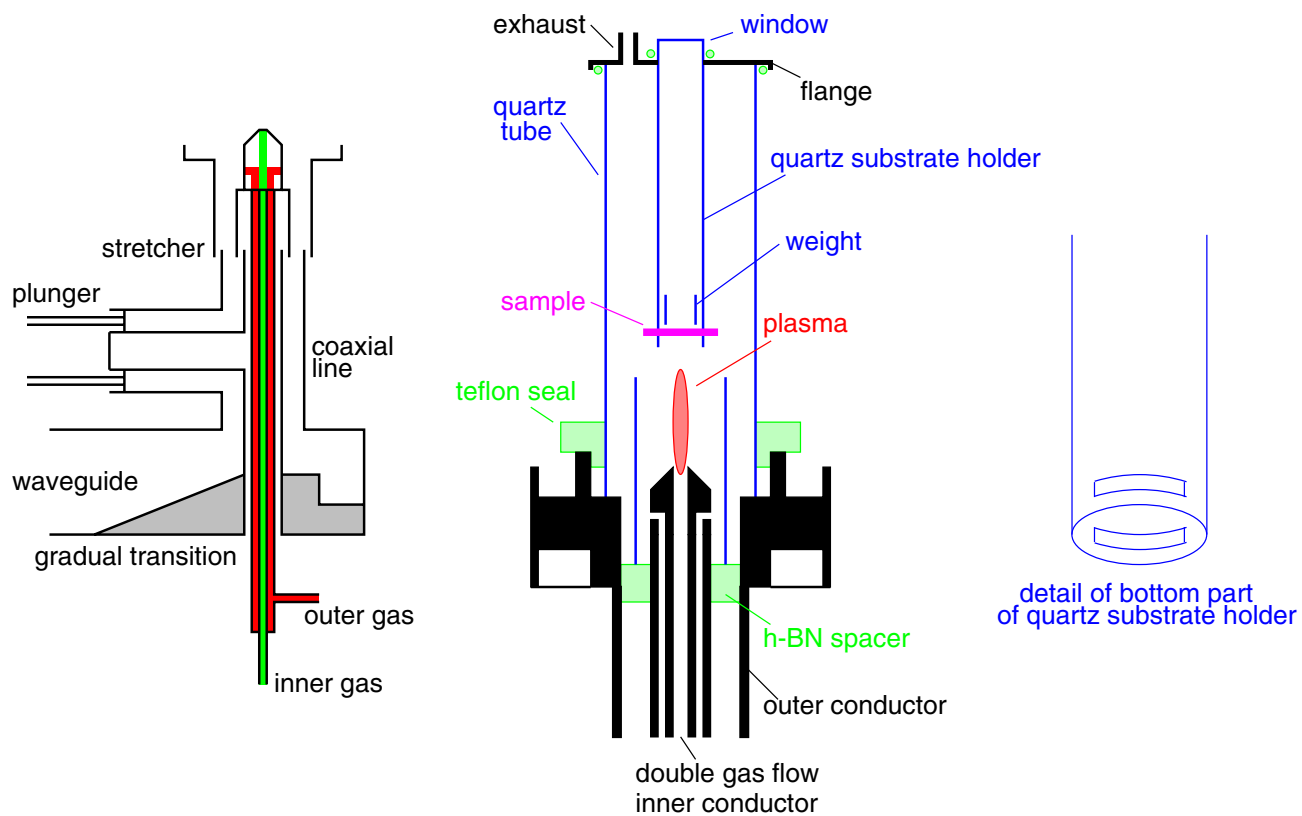

Figure 1. Detail drawing of the mw torch.

(This figure is in colour only in the electronic version)

a narrower quartz tube (see figure 1). This arrangement permits backside measurement of the substrate temperature by the Raytek Thermalert TX pyrometer. The pyrometer operates in the range of $770-2270 \mathrm{~K}$ and has a special optics focusing the measurement spot to $3 \mathrm{~mm}$ at the distance of $200 \mathrm{~mm}$.

For the CNT deposition $1000 \mathrm{sccm}$ of argon was flowing through the centre of the nozzle and an $\mathrm{H}_{2} / \mathrm{CH}_{4}$ mixture was added from the outer channel. The mw power was fixed at $400 \mathrm{~W}$. The deposition of CNTs was carried out on the silicon substrates with a double layer structure $-200 \mathrm{~nm}$ silicon oxide and thin $(5-15 \mathrm{~nm})$ iron catalyst films. The silicon oxide was prepared by PECVD in rf capacitively coupled low pressure glow discharge from the hexamethyldisiloxane/oxygen mixture and subsequently annealed at $970 \mathrm{~K}$ for $30 \mathrm{~min}$. It served as a barrier against metal catalyst diffusion into the silicon substrate. The annealing was necessary because the film contained high amounts of $\mathrm{OH}$ groups and hydrogen that would cause problems with the catalyst adhesion at the first stage of the CNT synthesis. A thin catalytic layer of iron $(5-15 \mathrm{~nm})$ was vacuum evaporated on the top of the silicon oxide.

Optical emission spectra were recorded by means of the Jobin-Yvon TRIAX 320 spectrometer with a fibre optics and CCD detector. The fibre was fixed at different distances from the nozzle along the discharge axis in order to study spatial changes in the plasma emission. The measurement spot integrated by the optics was $10 \mathrm{~mm}$. Appropriately, the spatial profiles were carried out with the same step. Overview spectra with two ranges of interests, $220-630 \mathrm{~nm}$ and $760-800 \mathrm{~nm}$, were recorded with the $1200 \mathrm{gr} \mathrm{mm}^{-1}$ grating whereas spectra with a higher resolution for rotational temperature determinations were measured with the grating of $2400 \mathrm{gr} \mathrm{mm}^{-1}$. The gas temperature approximated by rotational temperature in the case of a pure argon discharge was determined from the $\mathrm{OH}$ rotational structure of $3064 \AA$ system $\left({ }^{2} \Sigma \rightarrow{ }^{2} \Pi\right.$, ground state) using the Boltzmann plot. In the case of deposition mixtures, 
it was estimated as the rotational temperature from the $(0,0)$ rotational emission band of the $\mathrm{C}_{2}$ Swan system $\left({ }^{3} \Pi \rightarrow{ }^{3} \Pi\right.$, ground state). The procedure we used is discussed in detail in the next section.

The deposited samples were imaged by a scanning electron microscope (SEM) JOEL $6700 F$ equipped with an EDX analyser. Samples of nanotubes prepared by a positive replication technique were studied with a Philips CM12 STEM transmission electron microscope (TEM). Further information about the chemical structure was obtained by Raman spectroscopy with a Raman spectrometer DILOR-JOBIN YVON-SPEX using the LabRam confocal system and a $\mathrm{He}-\mathrm{Ne}$ laser excitation $(632.8 \mathrm{~nm}, 15 \mathrm{~mW})$ at room temperature.

\section{Results and discussion}

The mw torch discharges $(2.45 \mathrm{GHz})$ have already been extensively studied as excitation sources for the determination of elements using atomic emission spectroscopy (AES) (for overview, see Helium Plasma Issue of [16]). One of the widely used designs (regarding this application) is the so-called Torche à Injection Axiale (TIA) found in many modifications (e.g. [17-19]). The main part of the original TIA design [20] is a coaxial line mounted on a standard rectangular waveguide. In order to achieve good matching, moveable short circuits at the right side and bottom of the device are employed. The plasma is created at the top of the inner conductor (nozzle) of the coaxial line due to a high electric field that is present. The plasma gas flows through the inner conductor, which explains the name of this torch, i.e. the torch with axial (gas) injection.

Our design of the mw torch, used previously for AES, was rather similar to the original TIA device. The main differences were: broadband waveguide-coaxial transition, matching achieved entirely on the coaxial line and an open top of the coaxial line (no cap). In spite of these small details, the plasma parameters were comparable. This configuration was optimal for pure argon or argon with small admixtures. When using the $\mathrm{Ar} / \mathrm{H}_{2} / \mathrm{CH}_{4}$ deposition mixture the discharge was confined to the electrode tip and relatively high power was needed for its sustainment. This fact had negative consequences because at such high power levels the discharge often changed spontaneously into an arc-like form. Therefore, a new design of the nozzle (see figure 1) incorporated a dual flow injection as described above. Moreover, we suppressed the presence of air impurities by separation of the discharge with a closed quartz cylinder (see figure 1) using $1000 \mathrm{sccm}$ of argon. In this arrangement and in pure argon the discharge has a strong tendency to form several unstable plasma channels burning between the inner conductor and the quartz cylinder or the outer conductor. However, this design is superior as concerns ignition and sustaining the discharge when operated with the outer flow of $\mathrm{H}_{2} / \mathrm{CH}_{4}$. This results from the fact that the discharge in argon flowing through the centre is effectively ignited according to a principle similar to the hollow cathode. The plasma jet expands from the nozzle into the surrounding $\mathrm{H}_{2} / \mathrm{CH}_{4}$ atmosphere stabilizing the discharge and preventing the formation of interconductor arcing. The discharge does not burn directly in the molecular mixture but the energy from argon plasma is consequently transferred to it.

In the preliminary experiments with a simpler substrate holder the sample of dense and straight standing nanotubes was prepared in the mixture of $1000 \mathrm{sccm}, 300 \mathrm{sccm}$ and $50 \mathrm{sccm}$ of $\mathrm{CH}_{4}, \mathrm{H}_{2}$ and $\mathrm{Ar}$, respectively, with an iron catalyst on the $\mathrm{Si} / \mathrm{SiO}_{2}$ substrate at a temperature of about $970 \mathrm{~K}$ [15]. However, repeating the experiments it became clear that the reproducibility was poor. One of the reasons lay in the temperature control. It was only estimated by the pyrometer with disappearing filament in this arrangement. We also considered that the problem was positioning of the sample with respect to the electrode nozzle that was improved in the present set-up. 


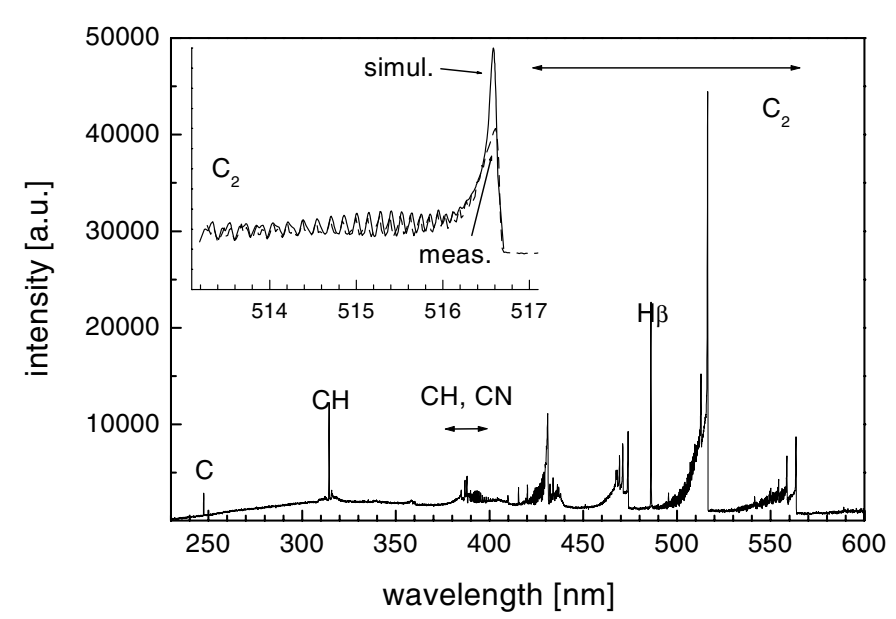

Figure 2. Survey of emission spectra from an mw torch $(400 \mathrm{~W})$ burning in $\mathrm{Ar}(1000 \mathrm{sccm})$ with outer $\mathrm{CH}_{4} / \mathrm{H}_{2}$ flow $\left(50 \mathrm{sccm} / 100 \mathrm{sccm}\right.$, respectively). In the inset, a zoom of $\mathrm{C}_{2}(0,0)$ rotational band of the Swan system is used for the calculation of rotational temperature. A comparison between measurement and simulation reveals a significant self-absorption.

Unlike in some other CVD systems the substrate is not heated by an external heater but by the discharge itself. Besides the power input the substrate temperature is controlled by the gas mixture and by the position of the substrate with respect to the nozzle electrode.

If the discharge was burning in pure argon the substrate temperature did not exceed $770 \mathrm{~K}$ i.e. the lower limit of the pyrometer. Since the substrate is heated mainly by a thermal exchange with the gas, the gas temperature in pure argon had to be relatively low. This fact was indeed confirmed by calculating the rotational temperature from the $\mathrm{OH}$ rotational structure of the $3064 \AA$ system. It was as low as $710 \pm 100 \mathrm{~K}$ for $1000 \mathrm{sccm}$ of Ar and $400 \mathrm{~W}$. We suppose that at the atmospheric pressure due to frequent collisions of the gas particles this temperature approximates the temperature of neutral gas. The low gas temperature is obviously a result of inefficient energy transfer from the hot discharge electrons to the thermal motion of heavy particles. On the other hand, the presence of argon promotes ionization and makes both the ignition and sustaining of the plasma easier.

The gas temperature in the case of deposition mixtures was estimated as the rotational temperature from the $(0,0)$ rotational emission band of the $\mathrm{C}_{2}$ Swan system. The comparison of measured as well as simulated rotational structures is shown in a graph (inset in figure 2). It reveals that relatively strong self-absorption takes place in our experiment. The hot $(T \approx 3600 \mathrm{~K}$ ) plasma column is surrounded by much cooler gas. The temperature of the quartz tube walls is under $500 \mathrm{~K}$ and thus the gas temperature at the walls cannot be much higher. Photons emitted from the central region are easily absorbed by surrounding gas because the discharge is operated at atmospheric pressure. Moreover, the lower level of the Swan system is the ground state of the $\mathrm{C}_{2}$ molecule. In outer colder gas layers there is a different population of rotational levels, i.e. higher rotational levels are not populated so much. Therefore, the absorption by lower populated rotational states is much higher than by empty ones. This results in reduced intensity of the $P$ lines forming the band head and consequently a deformation of its shape in this region (see figure 2). Additionally, the effect of self-absorption is also observed on the resolved rotational lines. The $R$ branch of the molecular spectrum, where the resolved lines with lower $(J>10)$ rotational numbers are easily observable, is affected much more than the resolved lines of the $P$ branch $(J>29)$. A similar disturbance of the rotational structure 




Figure 3. Boltzmann plot of resolved $P$ and $R$ lines of the $(0,0)$ rotational band in the $\mathrm{C}_{2}$ Swan system (for the mw torch parameters see figure 2). Since the lines with different rotational number $J$ were resolved in both the branches, a self-absorption of the $R$ branch caused a disturbance of the rotational structure resulting in a different slope of the line. The correct rotational temperature $T_{\mathrm{r}}$ however, can be determined from the $P$ branch.

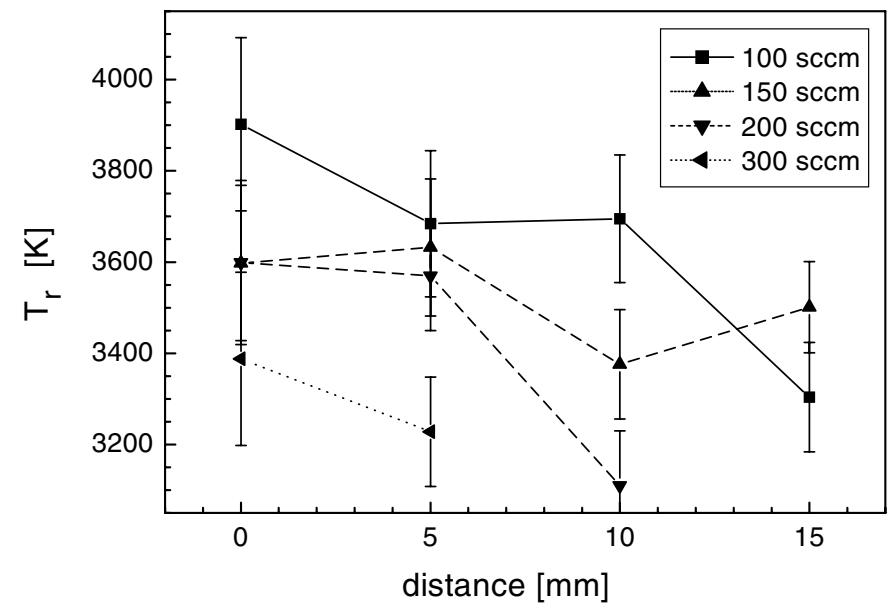

Figure 4. Rotational temperature $T_{\mathrm{r}}$ determined from the Boltzmann plot of the resolved $P$ lines in the $(0,0)$ rotational band of the $\mathrm{C}_{2}$ Swan system in dependence on the distance from the nozzle electrode and hydrogen flow rate given in the figure legend. Microwave power was $400 \mathrm{~W}$, $\mathrm{Ar}$ and $\mathrm{CH}_{4}$ flow rates were $1000 \mathrm{sccm}$ and $50 \mathrm{sccm}$, respectively.

due to the self-absorption has been reported for the $\mathrm{OH} 3064 \AA$ system [21]. As a result of this fact, the Boltzmann plot from the resolved $P$ and $R$ lines does not form one straight line but rather two lines with very different slopes, i.e. temperatures (see figure 3 ). However, one can still use the Boltzmann plot of the $P$ lines for a determination of the gas temperature.

Dependences of the rotational temperature, determined from the $P$ branch of the $\mathrm{C}_{2}$ rotational band on the position of the optical fibre with respect to the nozzle electrode and hydrogen flow rates, are given in figure 4 . We can see that the gas temperature slightly decreases with increasing distance from the electrode. The influence of hydrogen is more complicated. 


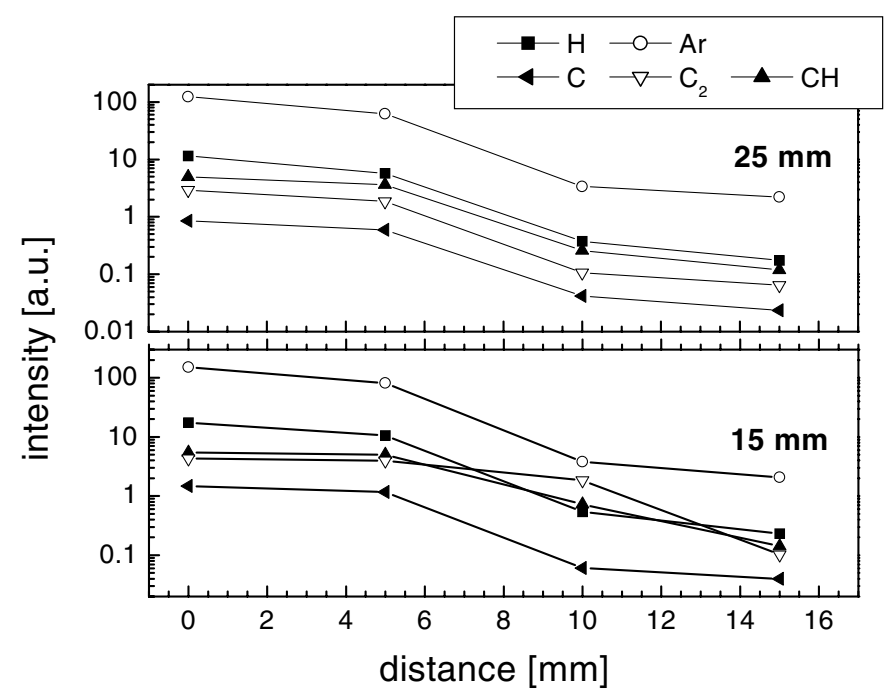

Figure 5. Intensities of selected atomic lines and molecular band heads (see text) in dependence on the distance from the electrode nozzle (horizontal axes in both graphs) and sample position (given in legend). Microwave power was $400 \mathrm{~W}$ and $\mathrm{Ar} / \mathrm{H}_{2} / \mathrm{CH}_{4}$ flow rates were $1000 \mathrm{sccm} / 300 \mathrm{sccm} / 50 \mathrm{sccm}$, respectively.

As mentioned above, in pure argon the gas temperature is quite low. As hydrogen is added, more energy goes to the thermal motion of the gas particles but more energy is also consumed in inelastic collisions. For small hydrogen flows the plasma plume is long and hot. When more hydrogen is added the plasma plume becomes shorter. A drop in temperature is caused not only by higher losses due to inelastic collisions but also by the extremely high thermal conductivity of hydrogen.

Besides the gas temperature the concentration of radicals is important for the deposition process too [22]. Related information can be also obtained from the emission spectra. The assignment of the observed spectral features was performed on the basis of the book by Pearse and Gaydon [23] and the NIST database of atomic emission lines [24]. An overview of the region $220-600 \mathrm{~nm}$ significant for a radical detection is given in figure 2 . The most dominant feature is the Swan system of the $\mathrm{C}_{2}$ molecule $(460-570 \mathrm{~nm})$. Several systems of $\mathrm{CH}$ emission, 3134, 3900 and $4300 \AA$ and atomic lines of hydrogen and carbon are also present. Air impurities in the arrangement with closed quartz tubes are rather low. Unlike in pure argon we do not observe any $\mathrm{N}_{2}$ and $\mathrm{OH}$ emission. The presence of a weak $\mathrm{CN}$ emission band cannot be completely excluded because it overlaps with the CH $3900 \AA$ system.

Relative intensities of the selected atomic lines and molecular band heads, $\mathrm{H}_{\beta}(486.13 \mathrm{~nm})$, Ar doublet (772.38 and $772.42 \mathrm{~nm}), \mathrm{C}(247.86 \mathrm{~nm})$ and $\mathrm{C}_{2}(0,0)$ rotational band of the Swan system $(516.52 \mathrm{~nm})$ and $\mathrm{CH}(0,0)$ rotational band of the $3134 \AA$ system $(314.49 \mathrm{~nm})$, are compared in figure 5 for two sample positions, 15 and $25 \mathrm{~mm}$ from the nozzle (flow rates of Ar, $\mathrm{H}_{2}$ and $\mathrm{CH}_{4}$ being 1000, 300 and $50 \mathrm{sccm}$ ). All the intensities decrease with increasing distance from the nozzle, i.e. in the recombining zone where the electron density also decreases [25]. The luminous part of the torch in this condition was $4.9 \mathrm{~mm}$ long as measured from a CCD image.

The position of the sample influences the line intensities ratios and the appearance of the plasma plume. The sample is an obstacle that disturbs the gas flow. We speculate that this effect is magnified by the construction of the sample holder because the quartz tube holder extends $4 \mathrm{~mm}$ below the sample towards the nozzle. Therefore, it functions as a gas trap. The intensity 


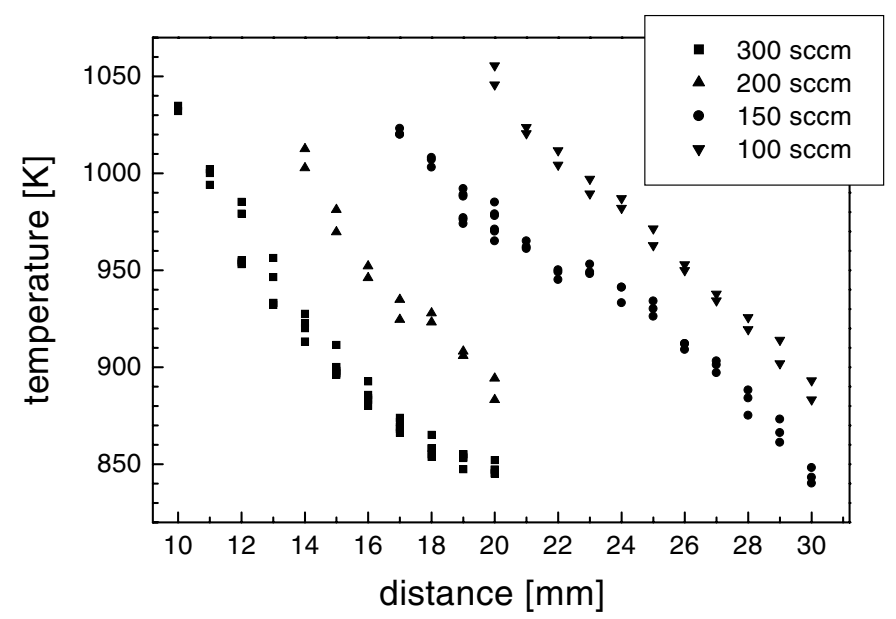

Figure 6. Substrate temperature as measured by a Raytek pyrometer in dependence on the substrate position (distance) with respect to the nozzle (horizontal axis) and $\mathrm{H}_{2}$ flow rate (given in the figure legend). Microwave power was $400 \mathrm{~W}, \mathrm{Ar}$ and $\mathrm{CH}_{4}$ flow rates were $1000 \mathrm{sccm}$ and $50 \mathrm{sccm}$, respectively.

of the $\mathrm{C}_{2}$ close to the sample is relatively stronger for a shorter sample distance. With the naked eye we observed that the plasma plume gets an orange haze close to the substrate when the sample approaches the plasma plume. Such colour is very similar to the appearance of an ordinary flame where carbon particles get heated and emit a black body radiation. Therefore, we assume that the stronger $\mathrm{C}_{2}$ emission accompanies the presence of carbon nanoparticles in the volume near the sample when the plasma plume is close enough.

In figure 6 the substrate temperatures for different hydrogen flows at variable distances of the substrate from the nozzle are compared. During these measurements the discharge was ignited in $1000 \mathrm{sccm}$ of $\mathrm{Ar}$ through the nozzle, the $\mathrm{H}_{2} / \mathrm{CH}_{4}$ mixture was added from outside and then the substrate was slowly moved down to the nozzle. At each measurement distance the temperature was recorded for about $45 \mathrm{~s}$ in order to allow for its stabilization. The starting and ending temperatures are both depicted in figure 6. The change in temperature within this time interval was, however, negligible when compared with the changes caused by the different substrate positions and the gas mixture. It is important to note that the length of the plasma plume also depends on the gas mixture. A small amount of $\mathrm{H}_{2} / \mathrm{CH}_{4}$ stabilizes the discharge into one straight plasma channel the length of which can be several centimetres. The luminous part of the torch for $100 \mathrm{sccm}$ of $\mathrm{H}_{2}$ and $50 \mathrm{sccm}$ of $\mathrm{CH}_{4}$ is $19.6 \mathrm{~mm}$ long whereas it shortens to $4.9 \mathrm{~mm}$ only from the mixture $300 / 50 \mathrm{sccm}$ of $\mathrm{H}_{2} / \mathrm{CH}_{4}$, respectively. The gas temperature decreases with the distance from the nozzle (see figure 4). The decrease in the length of the hot plasma zone with increasing $\mathrm{H}_{2}$ flow rate is the reason for a decrease in the substrate temperature at the fixed position of the substrate. This fact can be seen, for example, from the comparison of the temperatures of the substrates placed $20 \mathrm{~mm}$ from the electrode nozzle (see figure 6).

In the present configuration of the substrate holder various heating procedures during pretreatment and early deposition phases could be tested. After ignition of the torch in the argon flow with a removable auxiliary rod electrode, the substrate can be either immediately fixed at the chosen distance from the nozzle or moved from the far distance outside the plasma zone towards the nozzle. In the latter case the substrate moves slowly towards the hot plasma zone. Accordingly its temperature increases slowly up to the equilibrium temperature 


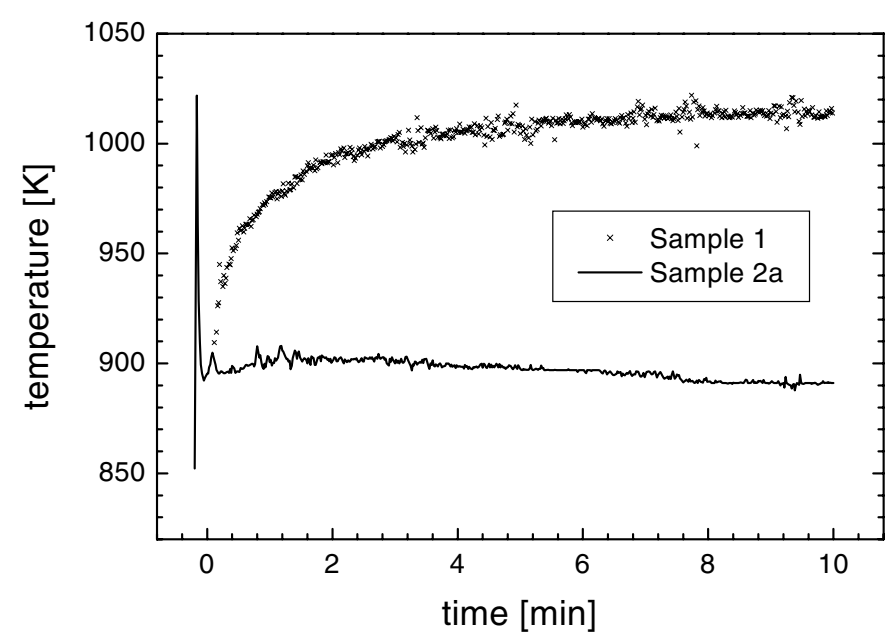

Figure 7. Substrate temperature recorded during the deposition of sample 1 and sample $2 \mathrm{a}$. In the first case the substrate was inserted directly into the stabilized deposition mixture $1000 \mathrm{sccm} / 300 \mathrm{sccm} / 50 \mathrm{sccm}$ of $\mathrm{Ar} / \mathrm{H}_{2} / \mathrm{CH}_{4}$, respectively, and fixed at the desired distance. In the latter case the substrate was fixed at the desired position and the flowmeters, with the same setting of $\mathrm{H}_{2}$ and $\mathrm{CH}_{4}$ flow rates, were opened afterwards. This causes the peaking of the temperature at the very beginning of the deposition.

given in figure 6. Additionally, the holder enables a sudden movement of the substrate to the position determined in advance. Since the substrate thermal capacity is low, its temperature increases abruptly in this case. Moreover, the temperature can be influenced by changing the deposition mixture as can be seen from figure 6 . We believe that the course of the substrate temperature is very important for a catalyst preparation and subsequent efficient CNT synthesis.

In the present paper, the synthesis of CNTs with the new substrate holder in similar conditions as before, i.e. the same gas mixture and the temperature about $970 \mathrm{~K}$, was studied also from the standpoint of pretreatment and an early deposition phase. Sample 1 was prepared without any pretreatment fixing the substrate directly into the deposition mixture at the desired distance from the nozzle. The temperature recorded from the seventh second of the deposition increased exponentially from 910 up to $1015 \mathrm{~K}$ (see figure 7). The sample surface after 15 min of deposition appeared to the eyes non-uniform and partially covered by a black deposit. The SEM micrograph revealed that on the most black places some amorphous carbon structures were prepared. The Raman spectra showed a high luminescence signal and two weak peaks at 1330 and $1606 \mathrm{~cm}^{-1}$. Surprisingly, dense and long CNTs were found at the sample edges only (see figure 8).

For samples $2 \mathrm{a}$ and $2 \mathrm{~b}$, the beginning phase differed from the approach used in case of the sample 1. The substrate was fixed at a distance of $15 \mathrm{~mm}$ in the pure argon torch and the deposition mixture ( $300 \mathrm{sccm}$ and $50 \mathrm{sccm}$ of $\mathrm{CH}_{4}$ and $\mathrm{H}_{2}$, respectively) was added afterwards. It caused an abrupt increase of the temperature to $1020 \mathrm{~K}$ and then the temperature stabilized in the range 890-900 K (see sample 2 a plot in figure 7). We think that this effect can be explained as follows: when the flow controllers are opened there is, at first, a small amount of the $\mathrm{CH}_{4} / \mathrm{H}_{2}$ coming through the nozzle. After a very short time the $\mathrm{CH}_{4}$ and $\mathrm{H}_{2}$ flow rates reach the preset values. If we take into account the results from figure 6 we can see that the substrate fixed at a certain distance from the nozzle is heated to a much higher temperature for a lower amount of hydrogen. Therefore, we expect that the high temperature at the beginning phase is the temperature that would reach the substrate for the low amount of hydrogen (or generally 


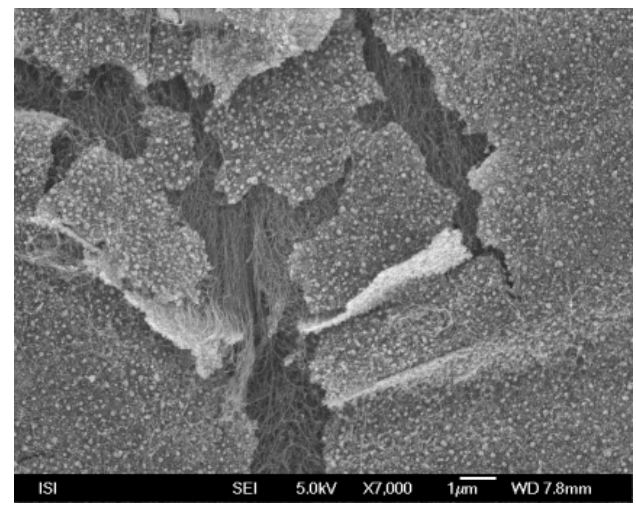

Figure 8. Dense and long nanotubes observed at the sample edges for slow substrate heating up to the deposition temperature of $1015 \mathrm{~K}$ (see figure 7, sample 1). The $\mathrm{Ar}, \mathrm{H}_{2}$ and $\mathrm{CH}_{4}$ flow rates were $1000 \mathrm{sccm}, 300 \mathrm{sccm}$ and $50 \mathrm{sccm}$, respectively.

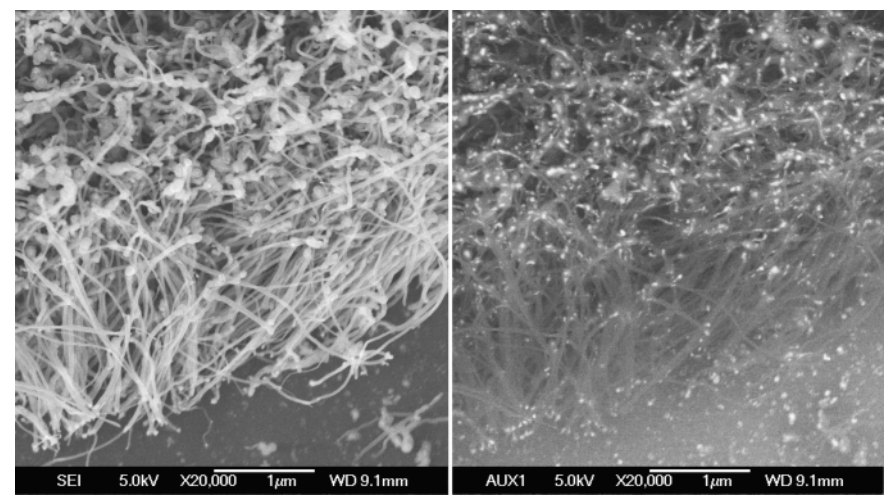

Figure 9. True secondary electron image (left) and back-scattered electron image (right) of the sample $2 \mathrm{~b}$ prepared from $1000 \mathrm{sccm} / 300 \mathrm{sccm} / 50 \mathrm{sccm}$ of $\mathrm{Ar} / \mathrm{H}_{2} / \mathrm{CH}_{4}$, respectively, with an abrupt temperature increase up to $1020 \mathrm{~K}$ at the early phase of deposition. The course of the substrate temperature within $10 \mathrm{~min}$ is given in figure 7 , sample $2 \mathrm{a}$.

for the low amount of molecular gas). Afterwards, the substrate temperature stabilizes at the temperature corresponding to the higher flow rates of $\mathrm{CH}_{4}$ and $\mathrm{H}_{2}$. The same heating procedure was tested for a very short deposition time on sample $2 \mathrm{~b}$. The above described deposition procedure turned out to be more efficient for CNT production because $0.3 \mathrm{mg}$ of the deposit was obtained on the substrate after only $25 \mathrm{~s}$. The SEM micrograph of sample $2 \mathrm{~b}$ in the true secondary electron imaging shows standing CNTs, $30 \mathrm{~nm}$ in average diameter, with the approximately three times larger nanoparticles on the top (see left figure 9). Imaging with the back-scattered electrons reveals that these spherical particulates are composed of an inner heavier core, iron and a lighter outer shell, carbon (see right figure 9). This fact was also confirmed by TEM micrographs.

The result described above corresponds with the model of the CNT growth by CVD and PECVD based on an adsorption of hydrocarbons or radicals on the metal particles and subsequent surface reactions leading to desorption of hydrogen and eventually some carbon bond breaking [26]. This mechanism can result in the base growth where the catalytic nanoparticle is left on the substrate and the tip growth with the nanoparticle is on the top 


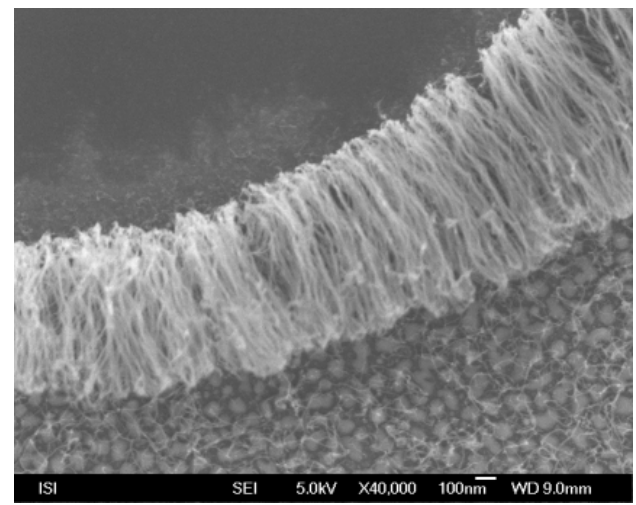

Figure 10. SEM micrograph of a different place on sample $2 b$ where thinner CNTs were found together with quite large iron particles.

of the CNT. According to the back-scattered SEM images our process follows the latter case. Since the deposition time was really short in the case of sample $2 \mathrm{~b}$ we can see some unutilized iron nanoparticles on the base of the substrate. However, the black deposit was not uniform. We found a place where the CNTs, only several nanometers thick, grew on the iron nanoparticles with a size similar to the first place on the sample (see figure 10). This result resembles the 'dissolution-precipitation' model of the CNT growth by high temperature methods, arc and laser ablation [27]. At this point it is worth noting that the synthesis of CNTs by the mw torch differs from the usual CVD and PECVD systems because of the high gas temperature.

\section{Conclusion}

Improved design of the substrate holder and optical emission spectroscopy of the discharge helped us to get more insight into the deposition process of the CNTs by the mw torch method reported previously. Within this deposition method the substrate is heated by the discharge itself to the required high deposition temperatures. We found that, for fixed mw power, the substrate temperature strongly depends on the substrate position with respect to the nozzle electrode and on the gas mixture, particularly the amount of $\mathrm{H}_{2}$. Therefore, any desired deposition temperature can be achieved by a combination of these two parameters. Additionally, slow or moderate heating of the substrate during an early deposition phase can be achieved and it has a significant effect on CNT synthesis. An abrupt increase of the temperature at the beginning of the deposition proves it is possible to increase the efficiency of the CNT synthesis. Areas of dense straight standing CNTs, $30 \mathrm{~nm}$ in average diameter, with approximately the same sized iron nanoparticles on their tops were found in accordance with the model of the growth mechanism in CVD and PECVD processes. However, the deposit was not uniform and a place with only several nanometers thick CNTs grown on much larger iron particles was also found. Taking into account the gas temperature in the torch, that can be as high as $3900 \mathrm{~K}$, and the appearance of the deposit in this particular place we can find similarities with the 'dissolution-precipitation' model of the CNT growth by arc discharge or laser ablation. The above summarized facts unfortunately show that the process of the CNT growth by the mw torch is not yet fully controllable and understood. Anyway, we believe that this simple and efficient arrangement without any vacuum equipment and external heaters has a potential for further improvement and its study is interesting also for understanding the mechanism of the CNT growth. 


\section{Acknowledgments}

This work was supported by the Czech Science Foundation under the contract GAČR 202/05/0607 and the Ministry of Education, Youth and Sports of the Czech Republic under the contract MSM002162241.

\section{References}

[1] Kajiura H, Tsussui S, Huang H and Murakami Y 2002 Chem. Phys. Lett. 364568

[2] Guo T, Nikolaev P, Thess A, Colbert D and Smalley R 1995 Chem. Phys. Lett. 24349

[3] Gao J, Umeda K, Uchino K, Nakashima H and Muraoka K 2003 Mater. Sci. Eng. 352308

[4] Küttel O, Gröning O, Emmenegger C and Schlapbach L 1998 Appl. Phys. Lett. 732113

[5] Hsu C, Lin C, Chang H and Kuo C 2002 Thin Solid Films 420225

[6] Han J-H, Lee T, Yoo J-B, Park C-Y, Jung T, Kim J, Yu S and Yi W 2003 J. Vac. Sci. Technol. B 211720

[7] Hofmann S, Ducati C and Robertson J 2003 Appl. Phys. Lett. 83135

[8] Boskovic B O, Stolojan V, Khan R, Haq S and Silva S 2002 Nature Mater. 1165

[9] Lin C, Leu I C, Yen J and Hon M 2003 Nanotechnology 15176

[10] Delzeit L, Mc IAninch, Cruden B, Hash D, Chen B, Han J and Meyyappan M 2002 J. Appl. Phys. 916027

[11] Denysenko I, Xu S, Long J, Rutkevych P, Azarenkov N and Ostrikov K 2004 J. Appl. Phys. 952713

[12] Nozaki T, Unno Y and Okazaki K 2002 Plasma Sources Sci. Technol. 111

[13] Chen C-K, Perry W L, Xu H, Jiang Y and Phillips J 2003 Carbon 412555

[14] Kikuchi T, Hasegawa Y and Shirai H 2004 J. Phys. D.: Appl. Phys. 371537

[15] Jašek O, Eliáš M, Zajíčková L, Kudrle V, Bublan M, Matějková J, Rek A, Buršík J and Kadlečíková M 2005 Mater. Lett. at press

[16] Carnaham J and Slavin W (ed) 1994 Spectrochim. Acta B 49 171R

[17] Rodero A, Garcia M C, Quintero M C, Sola A and Gamero A 1996 J. Phys. D.: Appl. Phys. 29681

[18] van der Mullen J A M and Jonkers J 1999 Spectrochim. Acta B 541017

[19] Jasinski M, Mizeraczyk J and Zakrzewski Z 2004 J. Adv. Oxid. Technol. 751

[20] Moisan M, Sauve G, Zakrzewski Z and Hubert J 1994 Plasma Sources Sci. Technol. 3584

[21] Marr G V 1968 Plasma Spectroscopy (Amsterdam: Elsevier) p 283

[22] Meyyappan M (ed) 2005 Carbon Nanotubes Science and Applications (London: CRC Press) p 102

[23] Pearse R W B and Gaydon A G 1950 The Identification of Molecular Spectra (London: Chapman and Hall)

[24] 2005 http://www.nist/gov

[25] Boidin M J G and Sandea M 2004 Spectrochim. Acta B 59929

[26] Meyyappan M (ed) 2005 Carbon Nanotubes Science and Applications (London: CRC Press) p 110

[27] Meyyappan M (ed) 2005 Carbon Nanotubes Science and Applications (London: CRC Press) p 79 